\section{Ragazzi L, Rocha M. Brumadinho: a engenharia de um crime. Belo Horizonte, Brasil: Editora Letramento; 2019. 256p.}

\author{
Tarcísio Márcio Magalhães Pinheiro \\ (https://orcid.org/0000-0002-1287-6304) ${ }^{1}$ \\ Naiana Andrade de Oliveira \\ (https://orcid.org/0000-0001-7805-3995) ${ }^{1}$ \\ Jandira Maciel da Silva \\ (https://orcid.org/0000-0002-9990-9323) ${ }^{1}$
}

\section{${ }^{1}$ Faculdade de Medicina, Universidade Federal de Mi- nas Gerais. Belo Horizonte MG Brasil.}

As tragédias humanas e ambientais oriundas dos rompimentos das barragens de rejeitos de minério de ferro de Fundão, na cidade de Mariana, em Minas Gerais, ano de 2015 e do Córrego do Feijão, na cidade de Brumadinho, também em Minas Gerais, no ano de 2019, ambas pertencentes à empresa Vale S.A., vêm merecendo inúmeras e distintas abordagens e estudos acadêmicos, técnicos, midiáticos e sociais ${ }^{1}$. Existem muitas polêmicas, conflitos e interesses em cena. Não há consenso quanto à própria denominação do evento (crime, acidente, tragédia, desastre, catástrofe), às suas determinações e causas (o modelo produtivo e o mercado, falhas organizacionais e coorporativas, conivências do aparelho de estado, o papel dos atores políticos), aos seus impactos (mortes, adoecimentos, agressões humanas e ambientais, perdas materiais), às suas consequências (reparações e indenizações, perdas de trabalho, de dignidade) e ao seu futuro (ressignificações, como recomeçar e reconstruir a vida, quando possível $)^{2,3}$. Este é o tema e o cenário desta obra que se propõe a relatar e analisar este relevante objeto de estudo e de intervenção, sobretudo para a Saúde Coletiva e seus campos da Saúde do Trabalhador e da Saúde Ambiental. Os autores realizaram uma minuciosa abordagem no campo do jornalismo investigativo, crítico e policial com um foco especial, mas não único, no trabalho desenvolvido por delegados da Polícia Federal (PF). A história do "crime" foi narrada ao longo de 17 capítulos. Foram levantados seus antecedentes, seus determinantes, seus responsáveis, suas vítimas, seus danos e as incertezas de seus desfechos.

A capa e o título do livro chamam a atenção do leitor: Brumadinho: a engenharia de um crime, livro -reportagem baseado na investigação dos delegados da Polícia Federal Cristiano Campidelli, Luiz Augusto Pessoa Nogueira, Rodrigo Teixeira e Roger Lima de Moura. No pano de fundo há uma imagem de destruição: móveis, lama e um crucifixo. A discussão conduzida nesta obra se articula em torno da engenharia de "crime" e está centrada na investigação policial.
Na introdução do livro Por que este livro?, os autores já estabelecem relações entre as rupturas de barragens em Brumadinho e em Mariana. Dizem: $E$ imperdoável ter existido Brumadinho após ter ocorrido Mariana. Relatam suas intenções de entender o papel de cada personagem na engrenagem de um desastre ambiental e humano com consequências imensuráveis, o que o fazem através de entrevistas, documentos públicos, depoimentos e processos judiciais. Os resenhistas acrescentam ainda, a observação participante, também empregado pelos autores.

Os três primeiros capítulos A terra em colapso, Rompeu de novo e Vamos prender todo mundo registram o momento da ruptura da Barragem I da Mina do Córrego do Feijão e as primeiras ações da PF. Os personagens e seus papéis ganham vida e transparência.

O capítulo 4, De volta a Fundão, retoma a história do rompimento da barragem em Mariana, os processos e inquéritos policiais realizados, os indiciamentos, os paralelos com Brumadinho, e os (des) caminhos judiciais. Um dos delegados entrevistados, emblematicamente diz: $\hat{E}$ diferente mas é igual. Nunca imaginei acontecer tudo de novo. No capítulo 5, Enterrar seus mortos, surgem as vozes, indignadas e sofridas dos familiares das vítimas fatais e as condições de precariedade, tensão e invisibilidade do trabalho no Instituto Médico-Legal.

No capítulo 6, De Mariana a Brumadinho, os autores enfocam alguns aspectos relativos às empresas envolvidas na ruptura da Barragem Fundão: a queda das ações nas bolsas de valores, a troca na presidência da Vale, os ataques e conveniências dos legislativos e de outras esferas políticas, as tentativas de recuperação das imagens arranhadas das empresas e uma posterior recuperação econômica.

O capítulo 7, A barragem é insegura, e a Vale sabe disso, é a parte central do livro. Há uma análise histórica de e-mails das empresas, dos seus relatórios internos de inspeção, dos laudos encaminhados a órgãos públicos, dos eventos com especialistas e consultores e das intervenções técnicas adotadas pelas empresas. A "engenharia do crime" é pormenorizada. São revelados os conflitos técnicos, as pressões gerenciais, as manipulações de dados e informações, o conhecimento do risco por parte dos ocupantes dos níveis de decisão e direção das empresas, até as graves falhas de equipamentos como os piezômetros, bem como o fator de segurança bem abaixo do recomendado internacionalmente.

Nos capítulos 8 e 9, Um alerta externo e Ninguém dorme, os autores narram os alertas e as resistências dos movimentos sociais e ambientais, e as apreensões e medos, pelos quais outras comunidades vivem diante do risco de novas rupturas de barragens em Minas Gerais. Nos capítulos 10 e 11, Ataque ao




cume e Sob pressão, são narrados os bastidores da preparação e execução do processo de busca e apreensão de documentos de funcionários dos mais altos escalões da Vale, a instalação do inquérito e os embates travados nas esferas legislativas estadual e federal. O capítulo 12, Em buscas das últimas joias, enfoca o trabalho exaustivo e penoso dos bombeiros na busca por corpos e segmentos, que se arrastou por meses. Aqui é interessante acrescentar que esta é uma categoria profissional essencial no cenário de devastação contemplado pela sociedade, mas também que sofreu impactos indeléveis em sua saúde física e mental.

A troca de acusações, de transferências de responsabilidades e de culpas entre as principais empresas acusadas - Vale e Tüv Süd - vêm à tona no capítulo 13, Jogo de empurra: os depoimentos. No capítulo 14, Os desastres vêm primeiro, as leis, depois, os autores denunciam o histórico de outras rupturas, a insuficiência legislativa e fiscalizatória das políticas de segurança de barragens no Brasil e as manipulações na construção e aplicação do Fator de Segurança de barragens. Todavia, demonstram que a ocorrência de grandes desastres na mineração tem possibilitado o avanço na legislação no país como a proibição da construção de barragens "a montante". O capítulo 15, À espera de justiça, traz a conclusão do inquérito da $\mathrm{PF}$, que pede o indiciamento de 13 funcionários e das empresas Vale e Tüv Süd por crime de falsidade ideológica e uso de documentos falsificados.

No capítulo 16, In Memoriam, são apresentados os nomes das 270 vítimas fatais, das quais 250 eram trabalhadores (131 diretos e 129 terceirizados) e 20 eram moradores ou turistas. Embora não tenha sido enfatizado pelos autores, é o processo e a organização do trabalho o determinante primário do "crime", em que os trabalhadores foram as suas maiores vítimas. $\mathrm{O}$ campo da Saúde do Trabalhador classifica este "crime" como Acidente Ampliado do Trabalho, ou seja, um evento grave, que tem sua origem no ambiente de trabalho e cujos efeitos extrapolamos muros da empresa, e atingem comunidades do entorno ${ }^{4}$. O capítulo 17, O que diz a Vale, seguindo uma tradição jornalística de ouvir todas as partes envolvidas (direito do contraditório), os autores publicam a resposta da Vale a respeito do rompimento e de suas ações em decorrência do mesmo. O Posfácio - Distopia traz uma posição reflexiva de indignação, de questionamento sobre o vasto histórico dos "crimes" passados e recentes envolvendo a mineração no Brasil. Termina com a frase: 20 de setembro de 2019 a lama de Mariana e a de Brumadinho ainda escorrem, destacando que a história não acabou. Encerra o livro um acervo de 29 fotos, com personagens e cenas do "crime".

Os autores, dois destacados jornalistas belo-horizontinos, produziram uma obra jornalística bem estruturada, instigante, sensível, crítica, numa linguagem agradável e objetiva, com riqueza e rigor de métodos e de conteúdo. Cumpriram com maestria seus objetivos. Além das 270 vidas humanas perdidas, das 11 pessoas ainda hoje desaparecidas, dos incontáveis danos ambientais, agravos à saúde de populações indígenas e ribeirinhas, agressões ao patrimônio cultural material e imaterial há um longo e penoso caminho de luta em busca de reparação humana, social e ambiental. Inúmeras ações judiciais estão em curso. A sociedade precisa se manter vigilante e participativa. Apesar do mérito pelo ágil e oportuno registro e análise, o livro tem as limitações inerentes ao fato de ser um breve recorte histórico de um fenômeno complexo e de curso longo. O cenário das relações saúde, trabalho e ambiente poderia ter um maior aporte e aprofundamento teórico para o entendimento de um dos maiores "crimes" socioambientais e "acidente" ampliado de trabalho no mundo. No entanto, seus autores foram precisos em focalizar os fatos a partir do campo de conhecimento do jornalismo investigativo. Mesmo com estas considerações, os resenhistas recomendam, fortemente, a leitura deste livro para profissionais, pesquisadores e estudantes do campo da Saúde Coletiva. Ele suscita reflexões imprescindíveis, a partir de um olhar diferente do da saúde, mas complementar no árduo trabalho de produzir conhecimento e aprendizado a partir de uma experiência profundamente devastadora. Brumadinho: a engenharia de um crime é uma importante contribuição para a formação e produção de conhecimento sobre saúde, trabalho e ambiente.

\section{Referências}

1. Pinheiro TMM, Polignano MV, Goulart EMA, Procópio JC, organizadores. Mar de Lama da Samarco na bacia do rio Doce: em busca de respostas. Belo Horizonte: Instituto Guaicuy; 2019.

2. Ministério do Trabalho. Superintendência Regional do Trabalho e Emprego de Minas Gerais. Relatório de análise de acidente: rompimento da barragem de rejeitos Fundão em Mariana (MG). Belo Horizonte: SRTE;2016.

3. Milanez B, Losekann C, organizadores. Desastre no Vale do Rio Doce; antecedentes, impactos e ações sobre a destruição. Rio de Janeiro: Folio Digital; Letra e Imagem; 2016.

4. Lacaz FAC, Porto MFP, Pinheiro TMM. Tragédias brasileiras contemporâneas: o caso do rompimento da barragem de rejeitos do Fundão/Samarco. Rev Bras Saude Ocup 2017; 42:e9. 